\title{
Addictive-Like Behaviors Increase The Risk of Suicide Behaviors in Chinese Middle School Students: A Latent Class Analysis
}

Chunyu Guo

Anhui Medical University

Xiaoqing Wang

Anhui Medical College

Zhengmei Xia

Anhui Medical University

Yingying Cui

Anhui Medical University

Jie Hu

Anhui Medical University

Yanni Xue

Anhui Medical University

Xuexue Huang

Anhui Medical University

Yuhui Wan

Anhui Medical University

Bao Zhang

the First Affiliated Hospital of Anhui Medical University

Xianbing Song

Anhui Medical College

Jun Fang

Sojo University

Shichen Zhang ( $\square$ zhangshichen@ahmu.edu.cn )

Anhui Medical University

\section{Research Article}

Keywords: addictive-like behaviors, suicide behaviors, adolescent, latent lass analysis, suicide ideation, suicide plan, suicide attempt

Posted Date: September 13th, 2021 
DOI: https://doi.org/10.21203/rs.3.rs-735158/v1

License: (c) (1) This work is licensed under a Creative Commons Attribution 4.0 International License. Read Full License 


\section{Abstract \\ Background}

In adolescents, multiple addictive-like behaviors (ALBs) occur frequently together which are likely to be associated with suicide behaviors (SBs), increasing the risk of suicide. This study aimed to clarify the potential subgroups of ALBs in Chinese adolescents, and examine the associations between different patterns of ALBs and SBs.

\section{Methods}

A total of 22,628 middle school students were enrolled in this study. Self-reported ALBs and SBs were investigated by questionnaires. Latent class analysis (LCA) was performed based on five ALBs [smoking, alcohol use (AU), diet pills use (DPU), screen time (ST), problematic mobile phone use (PMPU)]. Multivariate logistic regressions were used to examine the associations between the different patterns of ALBs and SBs.

\section{Results}

Four subgroups of ALBs were identified by LCA, including high-risk class (smoking/AU/DPU/PMPU/ST), moderate-risk class 1 (DPU/PMPU), moderate risk class 2 (smoking/AU/ST), and low-risk class. Compared with the low-risk class, all of the moderate-risk class 1, moderate-risk class 2 and high-risk class had higher risks of suicide ideation, suicide plan, and suicide attempt.

\section{Conclusions}

These findings suggested that the patterns of ALBs were related to SBs in Chinese adolescents. Accordingly, considerations of different classes of ALBs may be essential for developing effective preventive programs.

\section{Introduction}

Suicide behaviors (SBs) are the second leading cause of death of adolescents, and the major public health problem in China and around the world, which include suicide ideation, suicide plans, and suicide attempt [1]. In Chinese middle school students, the rate of suicide ideation, suicide plan, and suicide attempt were $20.8 \%, 7.69 \%$, and $6.3 \%$, respectively [2, 3]. A Canadian study showed the rate was $10.8 \%$ for suicide ideation and $3.0 \%$ for suicide attempt in adolescents [4]. In addition, $17 \%$ American teens had considered suicide, $14 \%$ have made suicide plan and $8 \%$ had attempted suicide, according to the Centers for Disease Control and Prevention [5]. SBs are significantly associated with completed suicide, depression, schizophrenia and, so on [6]. Adolescence is very vulnerable mostly because of their 
immature brain, limbic system, and prefrontal cortex, therefore, there is a great possibility for them to be influenced by the environment $[7,8]$. Therefore, they may be lacking the ability to judge their harmful behaviors properly, and get in trouble with some harmful behaviors such as mental health disorders and psychiatric disorders, and then SBs.

Addictive disorders include substance-use disorders (e.g., drug, alcohol, tobacco addiction, etc.), and behavioral disorders (e.g., game, internet, mobile phone addiction, etc.) with the characteristics of (1) long time and large amounts; (2) can't quit or cut down and impaired control; (3) craving and strong desire; and $(4)$ continued $[9,10]$. It has been known that mental health problems, nicotine, and alcohol could influence the brain maturation and development of adolescents [7], and substance-use disorders were associated with juvenile delinquency and suicide [11]. In recent studies, it has been cleared that mental health problems and smoking are strongly associated with SBs [12-14]. Alcohol drinking that is usually related to smoking $[14,15]$ was also reported to associate with SBs [16]. Adolescents are likely to misperceive their status of weight, especially, girls perceive themselves as overweight even though their weights are normal [17]. Diet pills using is one of the unhealthy ways for people to lose their weight. It has been reported that among American young adults, $10 \%$ of men and $17 \%$ of women use weight-lose products for losing weight [18]. Being obsessed with losing weight by using diet pills, may eventually cause depression, psychiatric disorders, and suicide $[19,20]$. In addition, non-substance addictive behaviors, such as long-time use of cell phones and media, are reported to be correlated with mental health problems, psychiatric disorders, and thought of suicide, probably due to the increase of sleep problems [21-24].

These findings suggest that the associations between addictive behaviors with SBs which are important and interesting, need to be further clarified. Under this circumstance, in this study, we focused on the addictive behaviors of smoking, alcohol use (AU), diet pills use (DPU), problematic mobile phone use (PMPU), and screen time (ST), and examined their potential relationship with SBs. Noteworthily, in this study, we adopted the method of self-report but not clinical diagnosis, we thus named these behaviors as addictive-like behaviors (ALBS) to differentiate from standard addictive behaviors. However, it should be noted that ALBs usually do not occur separately, but tends to occur simultaneously [25]. In recent years, a few researchers have begun to identify the distinct classes of ALBs [26] by latent class analysis (LCA). McFeeters et al. examined the subclasses of stressful life events related to suicide [27], and Bernanke et al. identified the relationship between mental health problems and SBs [28]. However, there are few studies directly paying attention to the associations between addictive behaviors and SBs based on LCA. So, it is important to consider multiple factors/behaviors and their interactions for the prevention of suicide in adolescents.

In this context, by using exploratory LCA, in this study we identified the potential classes of ALBs based on a large population of Chinese adolescents, and examined the associations between the classes of ALBs and SBs. This study may provide a new thought for suicide prevention and improve adolescents' mental health. 


\section{Methods}

\subsection{Data and Participants}

This study used information from a large cross-sectional survey in China, which was approved by the Ethics Committee of Anhui Medical University (approval number 20140087). The data were collected from November 2015 to January 2016. In this study, 23,137 adolescents (Aged 12 to 19 years) were enrolled from junior school and senior high school, located in six cities of China, including both urban and rural regions, by using multistage stratified cluster sampling. Six cities were selected by convenient sampling, including Shenyang (capital of Liaoning Province), Bengbu (Northeastern of Anhui province), Yangjiang (Southwest coast of Guangdong Province), Chongqing (one of China's four direct-controlled municipalities), Ulanchap (Central Inner Mongolia Autonomous Region) and Xinxiang (North of Henan Province). Then, eight schools (two rural junior and two senior high schools, two urban junior and two senior high schools) were selected in each region based on the stratified cluster sampling. Lastly, four to six classes were randomly selected from each grade (grades seven to twelve) in each school, all students from the selected classes were invited to the study, excluding participants who have a history of psychiatric disorders or are being treated with psychiatric medication (Participants with psychiatric disorders were primarily self-reported or reported by parents).

According to the principle of informed consent, the research staff explained the aim and process of the study to the students participating in the survey, and students were allowed to choose to participate or not. Students are required to complete the questionnaires during class time in about 20-30 minutes. The questionnaires were completed anonymously with unified instructions. A research staff was responsible for the quality control of the questionnaires to answer the questions from the recipients and for collecting and proofreading the questionnaire. Excluding the incomplete questionnaires (with more than $5 \%$ missing data), 22,628 valid questionnaires were received with an effective recovery rate of $97.8 \%$. The mean age of the participants in this study was $15.36(S D=1.79)$ years. Of the 22,628 participants, 10,990 students were male (48.6\%) and 11,638 were female (51.4\%).

\subsection{Measures}

Socio-demographic variables included sex, grade, place of residence, having any siblings, residing in school or commuting to school, parental educational level, self-reported family economy, and the number of friends.

Concerning SBs, according to the youth risk behavior surveillance system (YRBSS), the suicide ideation related question is "In the past 12 months, how many times have you ever think about killing yourself?"; the suicide plan related question is "how many times have you ever made some plan for killing yourself?"; and the suicide attempt related question is "In the past 12 months, how many times have you ever put any behaviors about killing yourself?". The answer was coded as a dichotomous variable (yes/no) [29]. 
The definition of smoking and AU were based on YRBSS from the Centers for Disease Control and Prevention [30]. Regarding current smoking status, the item is "How many days did you smoked in the last month?" with the options of "0" as 0 days, "1" as 1 to 9 days, "2" as 10 to 19 days, and " 3 " as 20 to 30 days. And about current AU status, the item is "How many days in the last month have you had at least one class of alcohol?" with the options of " 0 " as 0 days, " 1 " as 1 to 9 days, "2" as 10 to 19 days, and " 3 " as 20 to 30 days. For these two items, choose 0 as no and other options as yes [30]. DPU was measured with the item "Do you use diet pills or tea to lose their weight in the last month?", with "1" indicating none, " 2 " indicating only once, " 3 " indicating twice to three times, and " 4 " indicating more than four times. Participants not answering "none" were judged as they have DPU [31]. The validity of these items was demonstrated in previous studies [29].

PMPU was assessed via the Self-rating Questionnaire for Adolescent Problematic Mobile Phone Use (SQAPMPU), the standardized questionnaire for PMPU in adolescents [32]. It consists of 13 items that respond to a 5-point Likert scale (never, occasionally, sometimes, often, and always). Based on the prior literature, SQAPMPU global scores $\geq 28$ were judged as PMPU $[16,33,34]$. In this study, the Cronbach's alpha coefficient was 0.923 .

ST was assessed by the answers to the following questions, "On school days, how long about do you spend time on playing games or using the computer or smartphone to do something unrelated to your studies every day? (i.e. game console, TV show, computer, etc.)". And too long ST was defined as ST > 2 $\mathrm{h} /$ day according to the standard of the American Academy of Pediatrics and previous studies (American Academy of Pediatrics, 2001) [35].

\subsection{Statistical analysis}

Latent classes of ALBs were identified by LCA (Mplus version 7.4). In this study, we valued latent class models from one to five latent classes to ensure the most suitable number of latent classes. It is shown in previous work that Akaike Information Criteria (AIC) and Bayesian Information Criteria (BIC) criteria are the primary indices to select latent class model [36], but BIC is a more reliable indicator for the model with fewer parameters or with a large sample size more than one thousand. Accordingly, adjusted BIC (aBIC) via sample size calculation was used in this study to determine the number of latent classes [33]. The best suitable model is that both BIC and aBIC showed the lowest value [37]. In addition, LMR-LRT (LoMendell-Rubin Likelihood Ratio Test) and BLRT (Bootstrapped Likelihood Ratio Test) were also used in this study, which are useful tools for class enumeration, indicating the model of $k$-classes is better than the model of $k-1$ classes when there are statistical significance $(P<0.05)[33,37]$.

In addition, IBM SPSS version 23.0 for Windows was used for Chi-square analysis and logistic regression analysis. Chi-square tests were used to compare the prevalence of SBs among different demographic variables. Multiple logistic regression analysis was used to ensure the relationships between ALBs and SBs. And this analysis was adjusted by socio-demographic characteristics. $P<0.05$ was set as the statistical significance. 


\section{Results}

\subsection{Descriptive characteristics of the samples}

The prevalence of suicide ideation, suicide plan and suicide attempt were $14.1 \%(3,195), 7.3 \%(1,660)$ and $4.4 \%(1,000)$, respectively. Table 1 presented the occurrence of SBs by frequency socio-demographic characteristics. In this study, for all of the three SBs the higher rate was found in students of junior school, urban students, non-resident students, higher father's educational level, low self-reported family economy, and fewer friends than the correspondence groups ( $P<0.05$ for each). In addition, a higher rate of suicide ideation was found in the female and only child. And for suicide plan, the higher rate was in only child and higher mother's educational level ( $P<0.05$ for each) (Table 1$)$. 
Table 1

Descriptive socio-demographic characteristics of the sample in the study, $\mathrm{n}(\%)$

\begin{tabular}{|c|c|c|c|c|}
\hline Variable & Total sample & Suicide ideation & Suicide plan & Suicide attempt \\
\hline \multicolumn{5}{|l|}{ Sex } \\
\hline Male & $10990(48.6)$ & $1430(13.0)$ & $826(7.5)$ & $512(4.7)$ \\
\hline Female & $11638(51.4)$ & $1765(15.2)$ & $834(7.2)$ & $488(4.2)$ \\
\hline$\chi^{2}$ & & $21.63^{\star \star \star}$ & 1.02 & 2.90 \\
\hline \multicolumn{5}{|l|}{ Grade } \\
\hline Junior school & 11993(53.0) & $1809(15.1)$ & $963(8.0)$ & $586(4.9)$ \\
\hline Senior high school & $10635(47.0)$ & 1386(13.0) & $697(6.6)$ & $414(3.9)$ \\
\hline$\chi^{2}$ & & $19.56^{\star \star \star}$ & $18.06^{\star \star \star}$ & $13.17^{\star \star \star}$ \\
\hline \multicolumn{5}{|l|}{ Place of residence } \\
\hline Rural & 10882(48.1) & $1460(13.4)$ & $758(7.0)$ & $449(4.1)$ \\
\hline Urban & $11746(51.9)$ & $1735(14.8)$ & $902(7.7)$ & $551(4.7)$ \\
\hline$x^{2}$ & & $8.54^{\star \star}$ & $4.23^{*}$ & $4.27^{\star}$ \\
\hline \multicolumn{5}{|l|}{ Having any siblings } \\
\hline No & $9720(43.0)$ & 1458(15.0) & 772(7.9) & $448(4.6)$ \\
\hline Yes & 12908(57.0) & 1737(13.5) & $888(6.9)$ & $552(4.3)$ \\
\hline$x^{2}$ & & $10.89^{\star \star}$ & $9.22^{\star \star}$ & 1.45 \\
\hline \multicolumn{5}{|l|}{ Resident students } \\
\hline Yes & $11320(50.0)$ & $1525(13.5)$ & 758(6.7) & $414(3.7)$ \\
\hline No & 11308(50.0) & $1670(14.8)$ & $902(8.0)$ & $586(5.2)$ \\
\hline$\chi^{2}$ & & $7.84^{\star *}$ & $13.65^{\star \star \star}$ & $31.14^{\star \star \star}$ \\
\hline \multicolumn{5}{|c|}{ Father's educational levela } \\
\hline$<$ High school degree & $13006(57.5)$ & 1708(13.1) & $860(6.6)$ & $525(4.0)$ \\
\hline$\geq$ High school degree & $9424(41.6)$ & $1427(15.1)$ & $762(8.1)$ & $449(4.8)$ \\
\hline$x^{2}$ & & $18.36^{\star \star \star}$ & $12.64^{\star \star \star}$ & $6.97^{\star \star}$ \\
\hline
\end{tabular}

Note. ${ }^{a} 198$ students have no information about their father. ${ }^{b} 188$ students have no information about their mother; ${ }^{*} P<0.05 ;{ }^{* \star} P<0.01 ;{ }^{\star \star \star} P<0.001$. 


\begin{tabular}{|c|c|c|c|c|}
\hline Variable & Total sample & Suicide ideation & Suicide plan & Suicide attempt \\
\hline \multicolumn{5}{|c|}{ Mother's educational level ${ }^{\mathrm{b}}$} \\
\hline$<$ High school degree & $14335(63.4)$ & 1938(13.5) & $973(6.8)$ & $606(4.2)$ \\
\hline$\geq$ High school degree & $8105(35.8)$ & $1207(14.9)$ & $654(8.1)$ & $375(4.6)$ \\
\hline$x^{2}$ & & 8.10 & $12.64^{\star \star \star}$ & 1.96 \\
\hline \multicolumn{5}{|c|}{ Self-reported family economy } \\
\hline Bad & $3240(14.3)$ & $622(19.2)$ & $347(10.7)$ & 196(6.1) \\
\hline General & $16345(72.2)$ & $2090(12.8)$ & $1035(6.3)$ & 623(3.8) \\
\hline Good & $3043(13.4)$ & $483(15.8)$ & $278(9.1)$ & $181(6.0)$ \\
\hline$\chi^{2}$ & & $100.55^{\star \star \star}$ & $92.98^{\star \star \star}$ & $51.51^{\star \star \star}$ \\
\hline \multicolumn{5}{|l|}{ Number of close friends } \\
\hline$\leq 2$ & $5514(24.4)$ & 1017(18.4) & $560(10.2)$ & $324(5.9)$ \\
\hline $3 \sim 5$ & $9620(42.5)$ & $1225(12.7)$ & $580(6.0)$ & $345(3.6)$ \\
\hline$\geq 6$ & 7494(33.1) & $953(12.7)$ & $520(6.9)$ & $331(4.4)$ \\
\hline$\chi^{2}$ & & $112.43^{\star \star \star}$ & $90.41^{\star \star \star}$ & $43.50^{\star \star \star}$ \\
\hline
\end{tabular}

\subsection{Identification of latent class}

The rates of smoking, AU, DPU, and ST were found in a total of $2.8 \%(635), 16.8 \%(3799), 4.8 \%(1,086)$, and $16.3 \%(3,690)$ among Chinese adolescents, respectively. According to LCA, the patterns of ALBs were identified. As shown in Table 2, the five-class model didn't report the best log-likelihood value and the $P$ value of LMR-LRT and BLRT both were not statistically significant, it was thus not considered further. Both BIC (77654.647) and aBIC (77581.554) were found the lowest in the four-class model, which LMRLRT and BLRT were statistically significant $(P<0.001)$. Although, $P$ value of the LMR-LRT and BLRT test was also significant for 2-class and 3-class models, the 4-class model showed the lowest AIC, BIC, and aBIC values. These findings indicated the better fitness of this 4-class model than other models in the present study. Accordingly, we utilized the 4-class model and thus identified four latent classes (Table 2). 
Table 2

Model fit statistics for each of the fitted latent class analysis models.

\begin{tabular}{|llllllll|}
\hline Statistic & $\boldsymbol{d f}$ & AIC & BIC & aBIC & LMR-LRT & BLRT & Entropy \\
\hline 2 Classes & 11 & 77820.87 & 77909.17 & 77874.21 & $<0.0001$ & $<0.0001$ & 0.581 \\
\hline 3 Classes & 17 & 77531.15 & 77667.6 & 77613.58 & $<0.0001$ & $<0.0001$ & 0.78 \\
\hline 4 Classes & 23 & 77470.03 & 77654.65 & 77581.55 & $<0.0001$ & $<0.0001$ & 0.728 \\
\hline 5 Classes & 29 & 77473.07 & 77705.85 & 77613.69 & 0.0822 & 0.1935 & 0.717 \\
\hline $\begin{array}{l}\text { Note. } d f \text {. degrees of freedom; AIC: Akaike Information Criteria; BIC: Bayesian Information Criteria; } \\
\text { LMR-LRT: Lo-Mendell-Rubin Likelihood Ratio Test; BLRT: Bootstrapped Likelihood Ratio Tests. }\end{array}$ \\
\hline
\end{tabular}

As shown in Fig. 1, latent class 1 was recognized as the low-risk class, which was composed of 16113 $(71.2 \%)$ of the samples. In this group, the participants reported the lowest rate of all the four ALBs, and none of them reported PMPU (0\%). In contrast, latent class 4 was the high-risk class which included 3.3\% (747) of the samples. The majority of the students in this class reported smoking (28.8\%), AU (88.6\%), DPU (30.1\%), ST (69.6\%), and all of them were engaged in PMPU (100\%). The other two latent classes were called moderate-risk class 1 and moderate-risk class 2 , which contained $22.3 \%(5,055)$ and $3.2 \%$ (713) of the samples, respectively. Moderate-risk class 1 (latent class 2) showed high reporting rates on DPU (9.1\%) compared to moderate-risk class 2 and PMPU (79.1\%) which was thus defined as "DPU and PMPU" class; on the contrary, moderate-risk class 2 (latent class 3 ) showed high reporting rates on smoking (20.9\%), AU (71.6\%) and ST (44.5\%) which was thus defined as "smoking, AU and ST" class (Fig. 1).

\subsection{Multiple logistic regression analysis}

Table 3 showed the associations between the latent class of ALBs and SBs. After adjusting for significantly different socio-demographic characteristics, compared with the low-risk class, all other groups were seen to be positively related to SBs. Concerning suicide ideation the adjusted $O R(95 \% \mathrm{Cl})$ was 3.30 (3.03-3.59), 2.35 (1.91-2.88), and 6.08 (5.16-7.16) for moderate-risk class 1, moderate-risk class 2 , and high-risk class, respectively. Compared with the low-risk class, the results of suicide plan suggested the values of $O R(95 \% \mathrm{Cl})$ of moderate-risk class 1, moderate-risk class 2 and high-risk class were 3.20 (2.49-4.11), 3.92 (3.50-4.39), and 7.96 (6.58-9.61), respectively. Moreover, compared with low-risk class, the others classes had higher risks of suicide attempt $\left(O R_{\text {high-risk class }}=12.36,95 \% \mathrm{Cl}\right.$ : 9.95-15.35; $O R_{\text {moderate-risk class } 1}=5.59,95 \% \mathrm{Cl}$ : 4.81-6.49; $O R_{\text {moderate-risk class } 2}=4.17,95 \% \mathrm{Cl}$ : $3.07-$ 5.66) (Table 3). 
Table 3

Associations of suicide behaviors and latent class of ALBs in Chinese adolescents

\begin{tabular}{|c|c|c|c|c|c|c|}
\hline \multirow[t]{2}{*}{ Latent class of ALBs } & \multicolumn{2}{|c|}{ Suicide ideation } & \multicolumn{2}{|c|}{ Suicide plan } & \multicolumn{2}{|c|}{ Suicide attempt } \\
\hline & $\mathrm{n}(\%)$ & $\begin{array}{l}\text { Adjusted } \\
\text { OR (95\% } \\
\text { Cl) }\end{array}$ & $\mathrm{n}(\%)$ & $\begin{array}{l}\text { Adjusted } \\
\text { OR (95\% } \\
\mathrm{Cl})\end{array}$ & $\mathrm{n}(\%)$ & $\begin{array}{l}\text { Adjusted } \\
\text { OR (95\% } \\
\text { Cl) }\end{array}$ \\
\hline $\begin{array}{l}\text { High-risk class } \\
\text { (smoking } \\
\text { /AU/DPU/PMPU/ST) }\end{array}$ & $\begin{array}{l}285 \\
(38.2)\end{array}$ & $\begin{array}{l}6.08(5.16 \\
\sim 7.16)^{\star \star \star}\end{array}$ & 197(26.4) & $\begin{array}{l}7.96 \\
(6.58- \\
9.61)^{\star \star \star}\end{array}$ & $\begin{array}{l}153 \\
(20.5)\end{array}$ & $\begin{array}{l}12.36 \\
(9.95 \sim \\
15.35)^{\star \star \star}\end{array}$ \\
\hline $\begin{array}{l}\text { Moderate-risk class } \\
1 \\
\text { (DPU /PMPU) }\end{array}$ & $\begin{array}{l}1280 \\
(25.3)\end{array}$ & $\begin{array}{l}3.30(3.03 \\
\sim 3.59)^{\star \star \star}\end{array}$ & $725(14.3)$ & $\begin{array}{l}3.92 \\
(3.50- \\
4.39)^{\star \star \star}\end{array}$ & $\begin{array}{l}487 \\
(9.6)\end{array}$ & $\begin{array}{l}5.59 \\
(4.81 \sim \\
6.49)^{\star \star \star}\end{array}$ \\
\hline $\begin{array}{l}\text { Moderate-risk class } \\
2 \\
\text { (smoking/AU/ST) }\end{array}$ & $\begin{array}{l}126 \\
(17.7)\end{array}$ & $\begin{array}{l}2.35(1.91 \\
\sim 2.88)^{\star \star \star}\end{array}$ & $82(11.5)$ & $\begin{array}{l}3.20 \\
(2.49- \\
4.11)^{\star \star \star}\end{array}$ & $\begin{array}{l}54 \\
(7.6)\end{array}$ & $\begin{array}{l}4.17 \\
(3.07 \sim \\
5.66)^{\star \star \star}\end{array}$ \\
\hline Low-risk class & $\begin{array}{l}1504 \\
(9.3)\end{array}$ & Ref. & $656(4.1)$ & Ref & $\begin{array}{l}306 \\
(1.9)\end{array}$ & Ref. \\
\hline
\end{tabular}

Note. $O R$ : odds ratio; $C l$ : confidence interval; Adjusted $O R$ : adjusted for sex, grade, place of residence, having any siblings, resident student, educational level of father and mother, self-reported family economy, and number of friends; ${ }^{* \star \star} P<0.001$ compared with reference.

\section{Discussion}

In this study, we found SBs are a common phenomenon in adolescents in China. Moreover, we found female students showed more suicide ideation (15.17\%) than males (13.01\%), which is consistent with other reports $[4,38-40]$. Usually, females are more prone to have suicide ideation because of their predisposition to depression [40]. Meanwhile, a previous study showed that females had a higher risk of suicide attempt, mostly due to socioeconomic, mental disorders, school, and violence [41]. However, in this study, there was no apparent difference between suicide plan and suicide attempt between males and females, further investigations are needed to clarify this issue. Furthermore, in this study, we found that SBs were more in students of junior students, only child, urban students, non-resident students, higher parents' educational level, low self-reported family economy and fewer friends than the correspondence groups. And this result is partly consistent with previous studies [42, 43].

In the present study, we focused on the different patterns of ALBs, and examined the associations between latent classes of ALBs and SBs in a large Chinese sample. This modeling helps to link a broad range of factors including smoking, AU, DPU, PMPU, and ST behaviors. In this study, we identified four potential classes of ALBs, which is different from previous research examining multiple addictive behaviors among community participants [26], possibly because the types of ALBs are not completely 
consistent and the age range or country of the participants are different. Intriguingly, ALBs appeared to show two different clustering patterns in the moderate-risk classes. The moderate-risk class 1 (DPU/PMPU) had high rates of DPU and PMPU. Though previous studies did not show the relationship between DPU and PMPU directly, both unhealthy weight control behaviors (including DPU) and PMPU were reported to be related to adolescent mental health including suicide behaviors [44-46]. Usually, mobile phone use is related to screen media use, but in this study, ST wasn't clustered with PMPU, which may need further investigations to elucidate. In moderate-risk class 2 (smoking/AU/ST), students reported higher rates of smoking, $\mathrm{AU}$, and $\mathrm{ST}$. It is commonly known smoking and AU usually co-exist, which collaboratively influence the health of adolescents $[40,47]$. And the present study showed that adolescents who prefer smoking and AU are also more likely to have ST for a long time, which is consistent with previous studies [48]. Our results showed that the proportion of the high-risk class (smoking/AU/DPU/PMPU/ST) was only 3.3\%. However, given China's population base, it is necessary to identify and intervene in high-risk class (smoking/AU/DPU/PMPU/ST).

Our study further showed that students who engaged in more ALBs always exhibited a higher risk of SBs. Relative to the low-risk class, all three subclasses (the high-risk class, moderate-risk class 1 , and moderate-risk class 2) tend to have higher rates of SBs. It implied that certain ALBs usually occurred simultaneously, concurrently, and mutually affecting SBs, and adolescents exposed to similar conditions may show different outcomes because of the heterogeneity of ALBs. Therefore, different strategies should be developed by targeting different groups of adolescents, to prevent and control the ALBs and SBs. For the general population, such as the students of the low-risk class, series of courses about physical activity and health education to improve their health literacy maybe are effective $[33,49]$. Nevertheless, for the high-risk population, mindfulness-based intervention may be the good and necessary way [50-52]. Furthermore, the sense of weight control for adolescents was explained by Social Cognitive Theory that they imitate behaviors from role models, and under this condition, cognitive behavioral therapy may be useful to prevent from unhealthy losing weight by diet pills use [53-54]. In addition, physical activity is a significant way to reduce problematic smartphone use among adolescents [55]. So that for the moderate-risk class 1 , cognitive behavioral therapy with physical activity may be an appropriate way. Moreover, adolescents usually receive cigarettes and alcohol firstly from their friends, therefore group therapy, namely, peer education and developing adolescents' skills to say "no", will be an effective preventive strategy, [56]. Moreover, a previous study indicated that autonomous motivation acted as a significant mediator of changes in ST [57]. Taken together, it may be an effective intervention for moderate-risk class 2 to use group therapy by using peer education and autonomous motivation.

In this study, we used a relatively large sample size, which will better reflect the situation in the whole population. Furthermore, variables of ALBs used in this study covered not only substance use behaviors, but also non-substance use behaviors. More important we utilized the method of LCA to illustrate the association between ALBs and SBs, which will provide more reasonable and useful information for further establishing prevention programs, than single-factor analysis. All these will increase the reliability and applicability of this study. However, there are also some limitations in the present study. Firstly, we used self-reported data, which recall and reporting bias might be inevitable; meanwhile, a cross-sectional 
design could not imply causality. Moreover, not all kinds of ALBs were included in this study, and we focused on only one aspect of each behavior. In addition, as regards suicide, the psychological factor may play an important role, which was not included in this study. Further studies and considerations are thus warranted to overcome these barriers.

\section{Conclusion}

Taken together, similar to many previous studies, we reported here that SBs has a high prevalence rate among adolescents. By focusing on ALBs, we, through LCA analysis, found that ALBs do not act independently in SBs, but act synergistically, which may be related to the interrelated characteristics of ALBs. Namely, if we want to prevent SBs simply by changing a certain kind of ALBs, the result may be unsatisfactory. Therefore, compared with the intervention of some ALBs alone, more benefits can be obtained through the intervention of multiple ALBs in a specific group (high-risk class, moderate-risk class 1 and moderate-risk class 2). Many studies indicated that improvement of mindfulness-based intervention, group therapy, and physical activity can effectively intervene adolescents in risky addictive behaviors. We thus anticipated that SBs of adolescents could be prevented effectively by identifying groups with ALBs, and then developing effective methods targeting these groups of ALBs.

\section{Abbreviations}

\begin{tabular}{|ll|}
\hline ALBs & Addictive-like behaviors \\
\hline SBs & Suicide behaviors \\
\hline AU & Alcohol use \\
\hline ST & Screen time \\
\hline PMPU & Problematic mobile phone use \\
\hline DPU & Diet pills use \\
LCA & Latent class analysis \\
AIC & Akaike Information Criteria \\
\hline BIC & Bayesian Information Criteria \\
\hline LMR-LRT & Lo-Mendell-Rubin Likelihood Ratio Test $)$ \\
\hline BLRT & Bootstrapped Likelihood Ratio Test \\
\hline$d f$ & degrees of freedom \\
\hline OR & odds ratio \\
\hline$C l$ & confidence interval \\
\hline
\end{tabular}




\section{Declarations}

\section{Ethics approval and consent to participate}

The study was conducted according to the guidelines of the Declaration of Helsinki, and approved by the Ethics Committee of Anhui Medical University (approval number 20140087). Approvals from schools, parents and students were obtained before carrying out this survey. Signed informed consent was requested to each participating school, and the students were allowed to participate in the study upon receiving completed written consent form from their parents.

\section{Consent for publication}

Not applicable.

\section{Availability of data and materials}

The data presented in this study are available on request from the corresponding author.

\section{Competing interests}

The authors declare no conflict of interest.

\section{Authors' contributions}

Research design and obtained funding: SCZ and JF. Conducted the analysis and interpretation of data: CYG, YYC, ZMX, JH, YNX and XXH. Subjects' recruitment and data collection: SCZ, YHW, XBS, BZ and XQW. Writing-original draft preparation: CYG and XQW. Writing-review and editing: SCZ and JF. All authors read and approved the final manuscript.

\section{Funding}

This work was supported by the Domestic Visiting Study Project for Outstanding Young Talents in Colleges and Universities in Anhui Province in 2021 (gxgnfx2021183) and the Natural Science Foundation in Higher Education of Anhui (KJ2020A0209 and KJ2019ZD72). The funders had no role in study design, data collection and analysis, decision to publish, or preparation of the manuscript.

\section{Acknowledgments}

We frankly thank all participants and the schools involved in the survey, as well as other staff members on the scene.

\section{References}

1. Septier M, Stordeur C, Zhang J, Delorme R, Cortese S: Association between suicidal spectrum behaviors and Attention-Deficit/Hyperactivity Disorder: A systematic review and meta-analysis. 
Neuroscience and biobehavioral reviews 2019, 103:109-118.

2. Xiao Y, Chen Y, Meng Q, Tian X, He L, Yu Z, Wang Y: Suicide ideation and suicide plan in Chinese leftbehind children: Prevalence and associated factors. Journal of affective disorders 2019, 257:662668.

3. Harnod D, Harnod T, Lin CL, Shen WC, Kao CH: Increased Risks of Suicide Attempt and Suicidal Drug Overdose Following Admission for Head Injury in Patients with Depression. International journal of environmental research and public health 2019, 16(19).

4. Sampasa-Kanyinga H, Dupuis LC, Ray R: Prevalence and correlates of suicidal ideation and attempts among children and adolescents. International journal of adolescent medicine and health 2017, 29(2).

5. Greene N, Tomedi L, Reno J, Green D: The Role of Substance Use and Resiliency Factors on Suicidal Ideation among Middle School Students. The Journal of school health 2020, 90(2):73-80.

6. Guedria-Tekari A, Missaoui S, Kalai W, Gaddour N, Gaha L: Suicidal ideation and suicide attempts among Tunisian adolescents: prevalence and associated factors. The Pan African medical journal 2019, 34:105.

7. Arain M, Haque M, Johal L, Mathur P, Nel W, Rais A, Sandhu R, Sharma S: Maturation of the adolescent brain. Neuropsychiatric disease and treatment 2013, 9:449-461.

8. Slomp FM, Bara TS, Picharski GL, Cordeiro ML: Association Of Cigarette Smoking With Anxiety, Depression, And Suicidal Ideation Among Brazilian Adolescents. Neuropsychiatric disease and treatment 2019, 15:2799-2808.

9. Gorwood P, Le Strat Y, Ramoz N: Genetics of addictive behavior: the example of nicotine dependence. Dialogues in clinical neuroscience 2017, 19(3):237-245.

10. Maremmani AGI, Gazzarrini D, Fiorin A, Cingano V, Bellio G, Perugi G, Maremmani I: Psychopathology of addiction: Can the SCL90-based five-dimensional structure differentiate Heroin Use Disorder from a non-substance-related addictive disorder such as Gambling Disorder? Annals of general psychiatry $2018,17: 3$.

11. Mann JJ, Apter A, Bertolote J, Beautrais A, Currier D, Haas A, Hegerl U, Lonnqvist J, Malone K, Marusic A et al: Suicide prevention strategies: a systematic review. JAMA 2005, 294(16):2064-2074.

12. Berlin I, Hakes JK, Hu MC, Covey LS: Tobacco use and suicide attempt: Iongitudinal analysis with retrospective reports. PloS one 2015, 10(4):e0122607.

13. Li D, Yang X, Ge Z, Hao Y, Wang Q, Liu F, Gu D, Huang J: Cigarette smoking and risk of completed suicide: a meta-analysis of prospective cohort studies. Journal of psychiatric research 2012 , 46(10):1257-1266.

14. Murray EG, Isbister GK, McCrabb S, Halpin SA, Bonevski B: An examination of factors associated with tobacco smoking amongst patients presenting with deliberate self-poisoning. Journal of affective disorders 2020, 260:544-549.

15. Twyman L, Bonevski B, Paul C, Bryant J, West R, Siahpush M, D'Este C, Oldmeadow C, Palazzi K: Factors Associated With Concurrent Tobacco Smoking and Heavy Alcohol Consumption Within a 
Socioeconomically Disadvantaged Australian Sample. Substance use \& misuse 2016, 51(4):459470.

16. Zhang YY, Lei YT, Song Y, Lu RR, Duan JL, Prochaska JJ: Gender differences in suicidal ideation and health-risk behaviors among high school students in Beijing, China. Journal of global health 2019, 9(1):010604.

17. Deierlein AL, Malkan A, Litvak J, Parekh N: Weight Perception, Weight Control Intentions, and Dietary Intakes among Adolescents Ages 10(-)15 Years in the United States. International journal of environmental research and public health 2019, 16(6).

18. Hazzard VM, Borton KA, Bauer KW, Sonneville KR: Cross-sectional associations between genderlinked personality traits and use of weight-loss and muscle-building products among U.S. young adults. Eat Disord 2018, 26(5):418-429.

19. Elran-Barak R: The associations of healthful weight-control behaviors with psychological distress and changes in body mass index among young adults. Journal of health psychology 2019:1359105319840693.

20. Vrany EA, Hawkins MAW, Wu W, Stewart JC: Depressive symptoms and weight loss behaviors in U.S. adults. Eating behaviors 2018, 29:107-113.

21. Bonnaire C, Serehen Z, Phan O: Effects of a prevention intervention concerning screens, and video games in middle-school students: Influences on beliefs and use. Journal of behavioral addictions 2019, 8(3):537-553.

22. Liu J, Liu CX, Wu T, Liu BP, Jia CX, Liu X: Prolonged mobile phone use is associated with depressive symptoms in Chinese adolescents. J Affect Disord 2019, 259:128-134.

23. Oshima N, Nishida A, Shimodera S, Tochigi M, Ando S, Yamasaki S, Okazaki Y, Sasaki T: The suicidal feelings, self-injury, and mobile phone use after lights out in adolescents. Journal of pediatric psychology 2012, 37(9):1023-1030.

24. Riesch SK, Liu J, Kaufmann PG, Doswell WM, Cohen S, Vessey J: Preventing adverse health outcomes among children and adolescents by addressing screen media practices concomitant to sleep disturbance. Nursing outlook 2019, 67(4):492-496.

25. Hair EC, Park MJ, Ling TJ, Moore KA: Risky behaviors in late adolescence: co-occurrence, predictors, and consequences. The Journal of adolescent health: official publication of the Society for Adolescent Medicine 2009, 45(3):253-261.

26. Deleuze J, Rochat L, Romo L, Van der Linden M, Achab S, Thorens G, Khazaal Y, Zullino D, Maurage P, Rothen $S$ et al: Prevalence and characteristics of addictive behaviors in a community sample: $A$ latent class analysis. Addictive behaviors reports 2015, 1:49-56.

27. McFeeters D, Boyda D, O'Neill S: Patterns of Stressful Life Events: Distinguishing Suicide Ideators from Suicide Attempters. Journal of affective disorders 2015, 175:192-198.

28. Bernanke J, Galfalvy HC, Mortali MG, Hoffman LA, Moutier C, Nemeroff CB, Stanley BH, Clayton P, Harkavy-Friedman J, Oquendo MA: Suicidal ideation and behavior in institutions of higher learning: A latent class analysis. Journal of psychiatric research 2017, 95:253-259. 
29. Centers for Disease C, Prevention, Brener ND, Kann L, Shanklin S, Kinchen S, Eaton DK, Hawkins J, Flint KH, Centers for Disease C et al: Methodology of the Youth Risk Behavior Surveillance System2013. MMWR Recomm Rep 2013, 62(RR-1):1-20.

30. Kann L, McManus T, Harris WA, Shanklin SL, Flint KH, Queen B, Lowry R, Chyen D, Whittle L, Thornton $\mathrm{J}$ et al: Youth Risk Behavior Surveillance - United States, 2017. Morbidity and mortality weekly report Surveillance summaries 2018, 67(8):1-114.

31. Kann L: The Youth Risk Behavior Surveillance System: measuring health-risk behaviors. Am J Health Behav 2001, 25(3):272-277.

32. Tao S, Wu X, Wan Y, Zhang S, Hao J, Tao F: Interactions of problematic mobile phone use and psychopathological symptoms with unintentional injuries: a school-based sample of Chinese adolescents. BMC public health 2016, 16:88.

33. Yang R, Li D, Hu J, Tian R, Wan Y, Tao F, Fang J, Zhang S: Association between Health Literacy and Subgroups of Health Risk Behaviors among Chinese Adolescents in Six Cities: A Study Using Regression Mixture Modeling. Int J Environ Res Public Health 2019, 16(19).

34. Tao S, Wu X, Zhang Y, Zhang S, Tong S, Tao F: Effects of Sleep Quality on the Association between Problematic Mobile Phone Use and Mental Health Symptoms in Chinese College Students. International journal of environmental research and public health 2017, 14(2).

35. Waldmann T, Staiger T, Oexle N, Rusch N: Mental health literacy and help-seeking among unemployed people with mental health problems. J Ment Health 2020, 29(3):270-276.

36. Laska MN, Pasch KE, Lust K, Story M, Ehlinger E: Latent class analysis of lifestyle characteristics and health risk behaviors among college youth. Prevention science: the official journal of the Society for Prevention Research 2009, 10(4):376-386.

37. Carragher N, Adamson G, Bunting B, McCann S: Subtypes of depression in a nationally representative sample. Journal of affective disorders 2009, 113(1-2):88-99.

38. Ahmad N, Cheong SM, Ibrahim N, Rosman A: Suicidal ideation among Malaysian adolescents. AsiaPacific journal of public health 2014, 26(5 Suppl):63S-69S.

39. Sharma B, Nam EW, Kim HY, Kim JK: Factors Associated with Suicidal Ideation and Suicide Attempt among School-Going Urban Adolescents in Peru. International journal of environmental research and public health 2015, 12(11):14842-14856.

40. Silva RJ, dos Santos FA, Soares NM, Pardono E: Suicidal ideation and associated factors among adolescents in northeastern Brazil. ScientificWorldJournal 2014, 2014:450943.

41. Chau K, Kabuth B, Chau N: Gender and family disparities in suicide attempt and role of socioeconomic, school, and health-related difficulties in early adolescence. BioMed research international 2014, 2014:314521.

42. MacDonald R, Taylor J, Clarke D: The relationship between early suicide behaviors and mental health: results from a nine-year panel study. J Adolesc 2009, 32(5):1159-1172.

43. Zhang Y, Wu C, Yuan S, Xiang J, Hao W, Yu Y: Association of aggression and suicide behaviors: A school-based sample of rural Chinese adolescents. J Affect Disord 2018, 239:295-302. 
44. Hoseini-Esfidarjani SS, Negarandeh R, Janani L: The prevalence of weight-control behaviors and associated factors among adolescent girls in Tehran. Int J Adolesc Med Health 2020.

45. Kim JS, Seo Y: Associations Between Weight Perception, Unhealthy Weight Control Behavior, and Suicidal Ideation and Planning Among Korean Adolescents: A National Cross-Sectional Secondary Analysis. J Pediatr Nurs 2021, 56:e62-e69.

46. Xie H, Tao S, Zhang Y, Tao F, Wu X: Impact of problematic mobile phone use and insufficient physical activity on depression symptoms: a college-based follow-up study. BMC Public Health 2019, 19(1):1640.

47. Randall JR, Doku D, Wilson ML, Peltzer K: Suicidal behaviour and related risk factors among schoolaged youth in the Republic of Benin. PloS one 2014, 9(2):e88233.

48. Williams GC, Battista K, Leatherdale ST: An examination of how age of onset for alcohol, cannabis, and tobacco are associated with physical activity, screen time and BMI as students are preparing to graduate from high school. Prev Med Rep 2019, 15:100956.

49. Simonton AJ, Young CC, Johnson KE: Physical Activity Interventions to Decrease Substance Use in Youth: A Review of the Literature. Subst Use Misuse 2018, 53(12):2052-2068.

50. Schwebel FJ, Korecki JR, Witkiewitz K: Addictive Behavior Change and Mindfulness-Based Interventions: Current Research and Future Directions. Curr Addict Rep 2020, 7(2):117-124.

51. Li W, Garland EL, Howard MO: Therapeutic mechanisms of Mindfulness-Oriented Recovery Enhancement for internet gaming disorder: Reducing craving and addictive behavior by targeting cognitive processes. J Addict Dis 2018, 37(1-2):5-13.

52. Witkiewitz K, Bowen S, Harrop EN, Douglas H, Enkema M, Sedgwick C: Mindfulness-based treatment to prevent addictive behavior relapse: theoretical models and hypothesized mechanisms of change. Subst Use Misuse 2014, 49(5):513-524.

53. Thorlton J, Park C, Hughes T: Diet pills, powders, and liquids: predictors of use by healthy weight females. J Sch Nurs 2014, 30(2):129-135.

54. Smolak L, Levine MP: A two-year follow-up of a primary prevention program for negative body image and unhealthy weight regulation. Eat Disord 2001, 9(4):313-325.

55. Xiao T, Jiao C, Yao J, Yang L, Zhang Y, Liu S, Grabovac I, Yu Q, Kong Z, Yu JJ et al: Effects of Basketball and Baduanjin Exercise Interventions on Problematic Smartphone Use and Mental Health among College Students: A Randomized Controlled Trial. Evid Based Complement Alternat Med 2021, 2021:8880716.

56. Altay N, Toruner EK, Citak EA: Determination of smoking and drinking and preventive measures in adolescents. J Addict Nurs 2014, 25(2):94-102.

57. Babic MJ, Smith JJ, Morgan PJ, Lonsdale C, Plotnikoff RC, Eather N, Skinner G, Baker AL, Pollock E, Lubans DR: Intervention to reduce recreational screen-time in adolescents: Outcomes and mediators from the 'Switch-Off 4 Healthy Minds' (S4HM) cluster randomized controlled trial. Prev Med 2016, 91:50-57. 
Figures

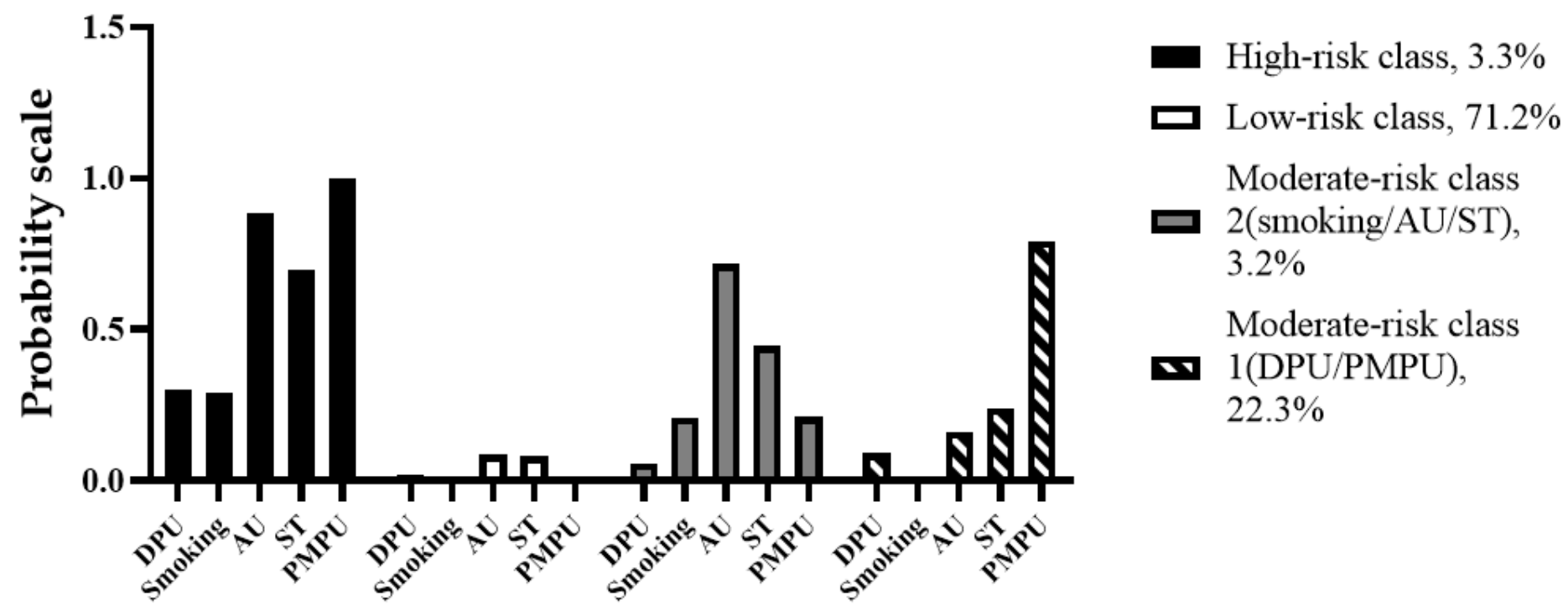

Figure 1

Four classes of addictive-like behaviors (ALBs) of the best-fitting four-class pattern 